\title{
Evaluation of Adverse Drug Reactions in Tertiary Care Hospital of Kolkata, West Bengal, India
}

\author{
Anjan Adhikari ${ }^{*}$, Niladri Bhattacharjee ${ }^{2}$, Sangita Bhattacharya ${ }^{1}$, Rania Indu ${ }^{1}$, Moumita Ray ${ }^{1}$ \\ 'Department of Pharmacology, R. G. Kar Medical College, Kolkata-700004, West Bengal, INDIA. \\ ${ }^{2}$ D.R B.C Roy College of Pharmacy \& Allied Health Sciences, Durgapur, West Bengal - 713212, INDIA.
}

\begin{abstract}
Objective: Drug is beneficial for the treatment, prevention or diagnosis of disease. However, adverse drug reactions (ADRs) associated with the use of drugs are also very common. Due to the lack of knowledge and awareness, many adverse incidents due to a drug remain unnoticed. Present study was conducted to evaluate the prevalence of adverse drug reactions in a tertiary care hospital in Kolkata, West Bengal, India. Method: Present study was an observational study based on the reports collected during July 2014 to June 2015 from different departments of a tertiary care hospital, with prior consent. The reports comprised of patients of age group ranging from 1 month to 85 years, of either sex. The causality assessment was done on the basis of "Naranjo's Assessment Scale" and severity assessment was done in accordance with "Hartwig and Siegel scale". Result: During the study period, among 529 prescriptions, adverse drug reactions was suspected in 287 patients. This comprised of 144 (50.17\%) females and $143(49.83 \%)$ males. According to Anatomical Therapeutic Chemical (ATC) Classification System, the drug mostly associated with adverse drug reactions was anti-infective agents $(63.07 \%)$. The causality assessment according to Naranjo Scale showed 5\% ADRs have definite, $40 \%$ probable and $55 \%$ possible correlation. Conclusion: In order to ensure a better treatment regimen and improve patients' compliance, it is essential to reduce and
\end{abstract}

prevent adverse drug reaction. Implementation of pharmacovigilance programs in the hospitals is thus essential to enhance the awareness regarding early detection, reporting, management and further prevention of Adverse Drug Reactions.

Key words: Adverse Drug Reaction (ADR), Pharmacovigilance, Tertiary care hospital, Anti-infective agents, Causality assessment.

Key messages: Adverse drug reaction (ADR) is a severe drawback of the therapeutics in the recent world. Pharmacovigilance is the practice of keeping records of these ADRs. The practice of pharmacovigilance is thus essential to decrease the incidence of adverse drug reaction occurring from different drugs.

Correspondence :

Dr. Anjan Adhikari, Associate Professor, Department of Pharmacology, R. G. Kar Medical College, 1, Kshudiram Bose Sarani, Kolkata-700004, West Bengal, INDIA.

Phone: 09831012503

Email: dradhikarianjankolkata@gmail.com

DOI: 10.5530/jyp.2017.9.62

\section{INTRODUCTION}

Drug is a chemical substance used in the treatment, cure, prevention, or diagnosis of disease or used to otherwise enhance physical or mental well-being. The World Health Organization (WHO) defined drug as "any substance or product that is used or intended to be used to modify or explore the physiological system, or pathological state in the benefit of the recipient". ${ }^{1}$ Drugs may be used for a limited duration, or on a regular basis for chronic disorders. Despite all the benefits of the drugs, the adverse reactions associated with them are also very common. Adverse drug reaction can be defined as "an appreciably harmful or unpleasant reaction, resulting from an intervention related to the use of a medicinal product, which predicts hazard from future administration and warrants prevention or specific treatment, or alteration of the dosage regimen, or withdrawal of the product". These are often preventable, cause of illness, which may require discontinuing a medication or modifying the doses, initial or prolongation of hospitalization. But sometimes it results in disability or can be life threatening even cause death.

WHO established the Programme for International Drug Monitoring. ${ }^{3}$ Pharmacovigilance (abbreviated PV or PhV) is the pharmacological science deals with detection, assessment, understanding and prevention of adverse effects and promotes the safe use of drugs. ${ }^{4}$ In 2005, National Pharmacovigilance Program (NPP) was introduced by the Ministry of Health and Family Welfare further, which was revised in July 2010. This program is monitored by the Central Drugs Standard Control Organization (CDSCO), New Delhi. ${ }^{5,6}$
In a study from South India, it was observed that $3.7 \%$ of the total hospitalized patients were suffering from ADR, among which $1.3 \%$ were fatal. $0.7 \%$ of the hospital admissions were due to ADRs. ${ }^{7}$ A study by Arulmani et al. revealed that among the collected ADR reports in the hospital, 3.4\% were confirmed ADR related cases which need to be hospitalised and $3.7 \%$ ADRs even developed in the patients during the time of hospital admission. ${ }^{8}$ In India there is lack of awareness regarding reporting ADR and its monitoring and thus monitoring the drug safety is one of the major problems in India. It is very necessary to enhance the awareness regarding early detection, reporting, management and further prevention of $\mathrm{ADR}$ and to ensure the drug safety and quality of life. Present study was conducted to evaluate the prevalence of adverse drug reactions in a tertiary care hospital in Eastern India.

\section{MATERIALS AND METHODS}

The present study of 'Adverse Drug Reactions' was an observational study based on the reports collected from different departments of R.G. Kar Medical College, Kolkata, West Bengal, India. Permission/consent from the Institutional Ethics Committee was taken before the study.

The ADR reports were collected from July 2014 to June 2015 in a tertiary care hospital, i.e., for twelve months. The reports were collected solely from the physicians. The reports containing information were collected from age group ranging from 1 month old to 85 years old of either sex

This is an open access article distributed under the terms of the Creative Commons Attribution-NonCommercial-ShareAlike 4.0 License, which allows others to remix, tweak, and build upon the work non-commercially, as long as the author is credited and the new creations are licensed under the identical terms. 
group. The patients with inadequate informations regarding diagnosis and prescribed drugs were excluded from the study.

The causality assessment was done based on "Naranjo's Assessment Scale"." A drug reaction is classified as definite, probable and possible according to the Naranjo's Assessment algorithm. Severity assessment was done in accordance with Hartwig and Siegel scale which classifies a drug reaction as mild moderate or severe. ${ }^{10}$

\section{RESULTS}

In this twelve months study (July 2014 -June 2015) in a tertiary care hospital in Kolkata, 529 prescriptions were randomly collected and analyzed, total of 2256 drugs were prescribed in these prescriptions during this time period. Average number of drugs per prescription was 4.26 [Table 1].

Evaluation of 529 prescriptions revealed 303 (57.3\%) adverse drug reactions among the 287 patients and that included 144 (50.17\%) females and $143(49.83 \%)$ males. The age distribution showed $104(36.30 \%)$ patients belonged to age group of 4 months to 40 years while 183 (63.70\%) belonged to the age group of 41-80 years.

Drug utilization pattern recognizes the problems in drug use, so educational programs or other interventions should be initiated to monitor the outcomes. ${ }^{11}$ In Anatomical Therapeutic Chemical (ATC) Classification System drugs are classified into 14 groups according to the therapeutic use, chemical and pharmacological attributes and route of administration. Figure 1 showed the distribution pattern of drugs causing adverse drug reaction according to ATC classification. The anti-infective agents showed the highest percentage $(63.76 \%)$ followed by drugs acting on alimentary tract \& metabolism (7.32\%), nervous system drugs (15.33\%).

Among the anti-infectives, anti-tuberculars were the most accounted antibiotic class $(60,32.79 \%)$ followed by beta lactums $(40,21.86 \%)$, antivirals $(30,16.39 \%)$, macrolides $(20,10.93 \%)$, quinolones $(12,6.56 \%)$, aminoglyosides ( $\mathrm{n}=18,9.84 \%)$, anti-malarials $(1,0.55 \%)$ \& others $(2,1.09 \%)$.

Adverse Drug reactions that have been reported here affected various organ systems, as shown in Figure 2. 50.17\% ADRs were related to skin and subcutaneous (144), 21.45\% affected the gastrointenstinal system (62), $10.56 \%$ (30) and $8.25 \%$ (23) addressed nervous system and general disorders respectively. Hepatobiliary disorders accounted for $4.62 \%$ (13) while $1.65 \%$ (5) were related to musculoskeletal \& connective tissue disorders. Respiratory and thoracic disorders showed up to $0.99 \%$ (3), whereas both blood \& lymphatic system disorders and psychiatric disorders related ADRs were found to be $0.66 \%$ (2). $0.33 \%$ (1) of ADRs were related to cardiac disorders, renal \& urinary disorders and endocrine disorders.
The Causality assessment was done in accordance with the Naranjo Scale which showed 5\% of Definite ADRs, Probable and Possible ADRs is 40\% and $55 \%$ respectively (Figure 3 ).

60 (19.8\%) ADRs were found to be mild, 212 (69.96\%) moderate and 30 (9.90\%) ADRs were severe according to the severity assessment. (Figure 4)

\section{DISCUSSION}

Pharmacovigilance is the program conducted worldwide to report various adverse reactions occurring due to drugs that are already being marketed. Present study reported adverse drug reaction cases from various departments of the tertiary care hospital for a duration of one year. During this period, 287 cases of Adverse Drug Reactions (ADR) were documented among 529 patients. Among patients, reported ADR $49.83 \%$ (143) were female whereas $50.17 \%$ (144) were male. Thus almost equal distribution of male and female patients with ADR were documented in this present study that complied with an ADR report in a tertiary care teaching hospital in South India. ${ }^{12}$ However, contradictory results were reported at a tertiary care hospital at Chhattisgarh, India that highlighted a higher prevalence of ADR among females (51.29\%) as compared to males (48.7\%). ${ }^{13}$ Individuals differ in their response to drug metabolism due to various factors that include differences in body mass index, genetic constitution, differences on the levels of various enzymes responsible for the drug metabolism. Majority of the ADRs (63.7\%) were detected among the age group 41-80 years, as was observed in a tertiary care hospital in Gujarat ( $>40$ years).$^{14}$ Similar results were observed in the studies conducted by different groups of researchers in South India, ${ }^{15}$ Chattisgarh. ${ }^{13}$ All these studies indicated prevalence of adverse drug reactions among the geriatric population. People of the older age group usually suffer from a number of disorders, thereby increasing the risk of adverse drug reactions. ${ }^{16}$

The drug mostly associated with ADR was found to be anti-infective agents $(63.07 \%)$, followed by nervous system drugs (15.33\%). A study in Brazil also indicated $40.7 \%$ of the ADRs were due to anti-infective agents. ${ }^{17}$ Analogous results were also reported by Sriram et al. ${ }^{17}$ and a regional pharmacovigilance centre in Portugal. ${ }^{18}$ Both these reports suggested antibiotics were the most common drug involved in adverse reaction. A study performed with Nigerian children by Priyadarshini et al. also reported antibiotics responsible for $67 \%$ of the ADRs. ${ }^{19}$ However, it was observed that Diuretics were mostly responsible for ADR in elderly patients. ${ }^{20}$ These observations therefore pose a threat on the use of antibiotics and thus clinicians must remain aware of the ill consequences of incorporating antibiotics in the therapeutic regimen of the patients.

Present study showed skin \& subcutaneous tissue disorders like urticaria, and erythematous rashes comprised of $50.17 \%$ of the ADR reports, as was observed among the patients in a tertiary care hospital in Northern

Table 1: Prescribing Indicators

\begin{tabular}{lcc}
\hline \multicolumn{1}{c}{ Drug Prescribing Indicator } & Amount & Percentage (\%) \\
\hline Total number of prescriptions analyzed & 529 & 100 \\
Total number of drugs prescribed & 2256 & 100 \\
Average number of drugs per encounter* & 4.26 & 100 \\
Total no. of adverse drug reactions reported & 287 & 54.25 \\
Total no. of male patients suffering from ADRs & 143 & 49.83 \\
Total no. of female patients suffering from ADRs & 144 & 50.17 \\
Patients belonged to age group of 4 months-40 years & 104 & 36.30 \\
Patients belonged to the age group of 41-80 years & 183 & 63.70 \\
\hline
\end{tabular}

*WHO prescribing indicators 


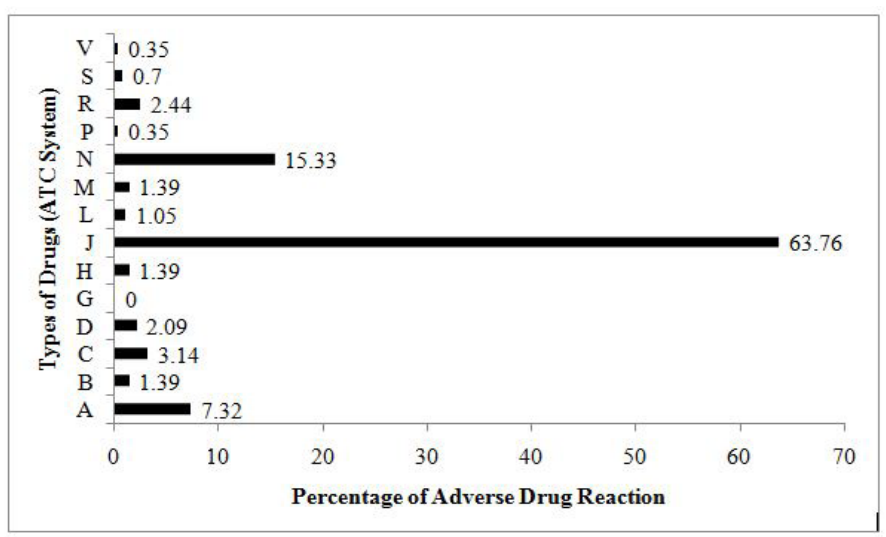

Figure 1: Distribution of drugs causing adverse drug reactions according to ATC Classification.

A- Alimentary tract and metabolism, B-Blood and blood forming organs, C- Cardiovascular system, D- Dermatologicals, G- Genito urinary system and sex hormones, $\mathrm{H}$-Systemic hormonal preparations, excluding sex hormones and insulins, J-Antiinfectives for systemic use, L- Antineoplastic and immunomodulating agents, M- Musculo-skeletal system, $\mathrm{N}$ - Nervous system, P- Antiparasitic products, insecticides and repellents, R- Respiratory system, S- Sensory organs, V-Various ( $\mathrm{n}=287$ ).

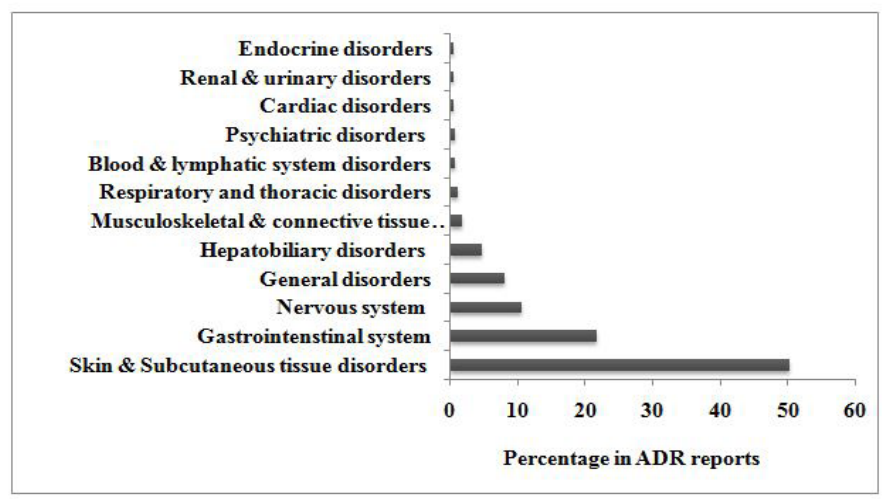

Figure 2: Distribution of adverse drug reactions in various organ systems $(n=287)$.

Brazil. ${ }^{21}$ Study conducted in Portugal was also in accordance with the present work, where it was reported $21 \%$ of the ADRs were skin manifestations. ${ }^{18}$ Rashes and skin problems were also prevalent (37\%) among the Nigerian children. ${ }^{19}$ However, Sriram et al., and Singh et al., reported contradictory results, documenting gastrointestinal problem to be $37 \%$ and $39.61 \%$, respectively, being most prevalent manifestation among patients with reported ADR. ${ }^{13,15}$ Present study reported $21.45 \%$ of the ADR cases were related to gastrointestinal problems.

The causality assessment of ADRs was done using the Naranjo scale. According to causality relationship, 55\% were reported as possible correlation because information on drug withdrawal was lacking or unclear. $40 \%$ were reported as probable and 5\% were reported definite causal relationship. However, no new signal was detected from the present study. These data correlated with the study of Sriram et al., Priyadharsini et al. and Jose et al. ${ }^{12,15,19}$ However in another study, in a tertiary care hospital in Kerala, India, $71.42 \%$ of the reactions were found to be probable, $18.36 \%$ of the cases possible, $10.2 \%$ definite and no reactions were unlikely. ${ }^{22}$ Present study documented $69.96 \%$ ADRs as moderate, $19.8 \%$ ADRs mild and $9.90 \%$ ADRs severe in 'Severity Assessment Scale' which was similar to the study carried by Shamna et al. and Singh et al..$^{13,22}$

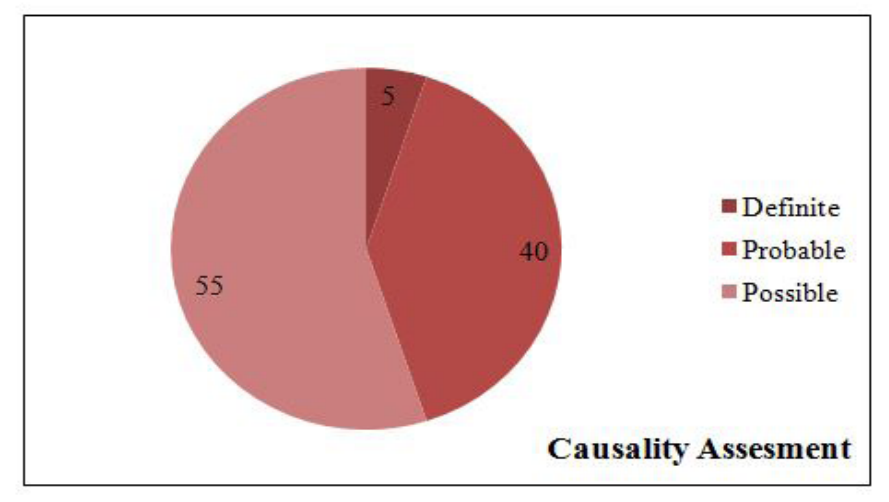

Figure 3: Causality assessment of ADRs according to Naranjo scale of assessment $(n=287)$.

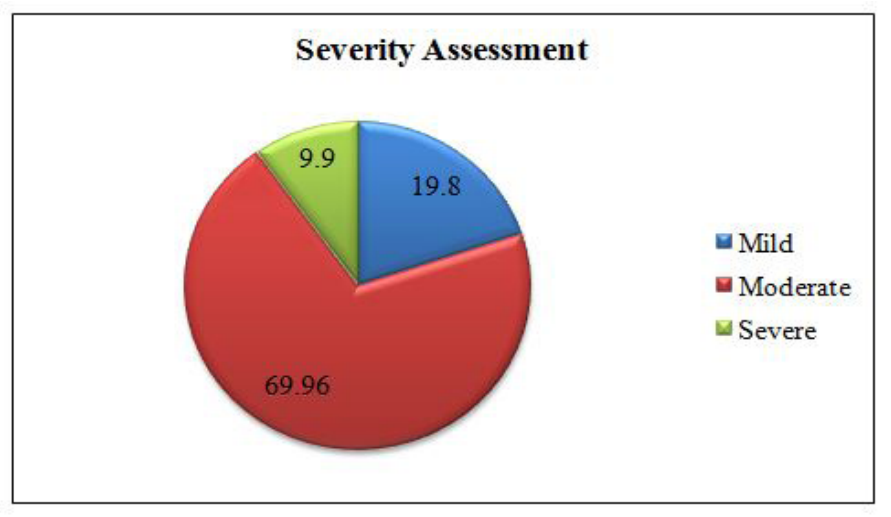

Figure 4: Severity assessment of the ADRs by 'Hartwig and Siegel scale'.

\section{CONCLUSION}

Thus it can be concluded that adverse drug reaction is a significant limitation to the success of therapeutics. In order to deal with this problem Pharmacovigilance program was initiated. It is essential to improve the quality and quantity of ADR reports and to promote surveillance programs in health care facilities. Present study depicted an overview of the different types of ADRs encountered in a tertiary care hospital. It highlighted that ADR is mostly prevalent among the elder individuals. Antibiotics were the most commonly causing ADR and mainly from skin problems. Pharmacists and other health care providers should join hands together to improve the scenario. Detection, prevention and treatment of ADR will not only improve the quality of life of the patient but will also reduce the cost. Thus, implementation of pharmacovigilance programs in the hospitals is essential to ensure safe pharmacotherapy and improve patient compliance.

\section{ACKNOWLEDGEMENT}

We take immense pleasure in thanking Principal, R.G. Kar Medical College, Kolkata, for permitting us to conduct this project in this esteemed Institution. We are also indebted to the Adverse Drug Reaction Monitoring Centre (Pharmacovigilance Programme of India,Indian Pharmacopoeia Commission,Ghaziabad), Department of Pharmacology, R.G. Kar Medical College, Kolkata, West Bengal, India, for their support and guidance, throughout this study. 


\section{CONFLICT OF INTEREST}

There is no conflict of interest.

\section{ABBREVIATIONS USED}

ADR: Adverse Drug Reaction; ATC Classification System: Anatomical Therapeutic Chemical Classification System; WHO: World Health Organization; PV or PhV : Pharmacovigilance; NPP: National Pharmacovigilance Program; CDSCO: Central Drugs Standard Control Organization.

\section{REFERENCES}

1. Sharma HL, Sharma KK. General Principles of Pharmacology. Principles of Pharmacology. 2nd ed. New Delhi: Paras Medical Publishers; 2011. p. 1.

2. Edwards R, Aronson JK. Adverse drug reactions: definitions, diagnosis, and management. The Lancet. 2000;356(9237):1255-9. https://doi.org/10.1016/ S0140-6736(00)02799-9.

3. Venulet J, Helling-Borda M. WHO's International Drug Monitoring - The Formative Years, 1968-1975 Preparatory, Pilot and Early Operational Phases. Drug Saf. 2010;33(7):1-23. https://doi.org/10.2165/11532410-000000000-00000; PMid:20553053

4. Jeetu G, Anusha G. Pharmacovigilance: A Worldwide Master Key for Drug Safety Monitoring. Journal of Young Pharmacists : JYP. 2010;2(3):315-20. https:// doi.org/10.4103/0975-1483.66802; PMid:21042493 PMCid:PMC2964775.

5. Abubakar AR, Simbak NB, Haque M. Drug safety surveillance: modern trends and industrial action. J Young Pharm. 2015;7(2):69-75. https://doi.org/10.5530/ jyp.2015.2.3

6. Amrita P, Singh SP. Status of spontaneous reporting of adverse drug reaction by physicians in Delhi. Indian J Pharm Pract. 2011;4(2):29-36.

7. Ramesh M, Pandit J, Parthasarathi G. Adverse drug reactions in a south Indian hospital - Their severity and costinvolved. Pharmacoepidemiol Drug Saf. 2003;12(8):687-92. https://doi.org/10.1002/pds.871; PMid:14762985.

8. Arulmani R, Rajendran SD, Suresh B. Adverse drug reaction monitoring in a secondary care hospital in South India. Br J Clin Pharmacol. 2008;65(2): 210-6. https://doi.org/10.1111/j.1365-2125.2007.02993.x; bPMid:17662089 PMCid:PMC2291214.

9. Naranjo CA, Busto U, Sellers EM, Sandor P, Ruiz I, Roberts EA, et al. A method for estimating the probability of adverse drug reactions. Clin Pharmacol Ther. 1981;30(2):239-45. https://doi.org/10.1038/clpt.1981.154; PMid:7249508.

10. Hartwig SC, Siegel J, Schneider PJ. Preventability and severity assessment in reporting adverse drug reactions. Am J Hosp Pharm. 1992;49(9):2229-32. PMid:1524068.
11. Guidelines for ATC classification and DDD assignment. WHO Collaborating Centre for Drug Statistics Methodology. 2012. Available from: http://www. whocc.no/filearchive/publications/1_2013guidelines.pdf

12. Jose J, Rao PG. Pattern of adverse drug reactions notified by spontaneous reporting in an Indian tertiary care teaching hospital. Pharmacol Res. 2006;54(3):226-33. https://doi.org/10.1016/j.phrs.2006.05.003; PMid:16781163.

13. Singh $H$, Dulhani $N$, Kumar BN, Singh P Tewari P Nayak K. A Pharmacovigilance Study in Medicine Department of Tertiary Care Hospital in Chhattisgarh (Jagdalpur), India. JYoung Pharm. 2010;2(1):95-100. https://doi.org/10.4103/09751483.62222: PMid:21331200 PMCid:PMC3035895.

14. Kathiria JM, Sattigeri BM, Desai PM, Patel SP. A Study Of Adverse Drug Reactions In Patients Admitted To Intensive Care Unit Of A Tertiary Care Teaching Rural Hospital. Int J Pharm Pharm Sci. 2013;5(1):160-3

15. Sriram S, Ghasemi A, Ramasamy R, Devi M, Balasubramanian R, Ravi TK, et al. Prevalence of adverse drug reactions at a private tertiary care hospital in south India J Res Med Sci. 2011;16(1):16-25. PMid:21448378 PMCid:PMC3063432.

16. Ramanath K, Nedumballi S. Assessment of Medication-Related Problems in Geriatric Patients of a RuralTertiary Care Hospital. Journal of Young Pharmacists: JYP. 2012;4(4):273-8. https://doi.org/10.4103/0975-1483.104372; PMid:23492987 PMCid:PMC3573380.

17. Visacri MB, de Souza CM, Sato CMS, Granja S, Marialva M, Mazzola PG, et al. Adverse Drug Reactions and quality deviations monitored by spontaneous reports. Saudi Pharmaceutical Journal. 2015;23(2):130-7. https://doi. org/10.1016/j.jsps.2014.06.008: PMid:25972731 PMCid:PMC4421093.

18. Marques J, Ribeiro-Vaz I, Pereira AC, Polónia J. A survey of spontaneous reporting of adverse drug reactions in 10 years of activity in a pharmacovigilance centre in Portugal. Int J Pharm Pract. 2014;22(4):275-82. https://doi.org/10.1111/ ijpp.12078; PMid:24188533.

19. Priyadharsini R, Surendiran A, Adithan C, Sreenivasan S, Sahoo FK. A study on adverse drug reactions in paediatric patients. J. Pharmacol. Pharmacother. 2011:2(4):277-80. https://doi.org/10.4103/0976-500X.85957; PMid:22025857 PMCid:PMC3198524.

20. Haile DB, Ayen WY Tiwari P. Prevalence and Assessment of Factors Contributing to Adverse Drug Reactions in Wards of a Tertiary Care Hospital, India Ethiopian Journal of Health Sciences. 2013;23(1):39-48. PMid:23559837 PMCid:PMC3613814

21. Lobo MG, Pinheiro SM, Castro JG, Momenté VG, Pranchevicius MC. Adverse drug reaction monitoring: support for pharmacovigilance at a tertiary care hospital in Northern Brazil. BMC Pharmacol. Toxicol. 2013:14(1):5. https://doi. org/10.1186/2050-6511-14-5; PMid:23298396 PMCid:PMC3554560.

22. Shamna M, Dilip C, Ajmal $M$, Linu Mohan $P$, Shinu $C$, Jafer $C P$, et al. A prospective study on Adverse Drug Reactions of antibiotics in a tertiary care hospital. Saudi Pharmaceutical Journal. 2014:22(4):303-8. https://doi. org/10.1016/j.jsps.2013.06.004; PMid:25161373 PMCid:PMC4142362.

Article History: Submission Date :17-10-2016; Revised Date : 08-02-2017; Acceptance Date : 07-03-2017.

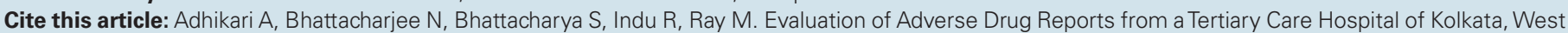
Bengal, India. J Young Pharm, 2017;9(3):311-4. 